\title{
The protective role of amla (Emblica officinalis Gaertn.) against fructose-induced metabolic syndrome in a rat model
}

\author{
Hyun Young Kim ${ }^{1,2}$, Tsutomu Okubo $^{3}$, Lekh Raj Juneja ${ }^{3}$ and Takako Yokozawa ${ }^{2} *$ \\ ${ }^{1}$ Department of Food Science, Jinju National University, 150 Chilamdong, Jinju 660-758, Korea \\ ${ }^{2}$ Institute of Natural Medicine, University of Toyama, 2630 Sugitani, Toyama 930-0194, Japan \\ ${ }^{3}$ Bio-nutrition Division, Taiyo Kagaku Co. Ltd, 1-3 Takaramachi, Yokkaichi 510-0844, Japan
}

(Received 17 April 2009 - Revised 10 August 2009 - Accepted 11 August 2009 - First published online 2 November 2009)

We investigated the effects of amla (Emblica officinalis Gaertn.) on fructose-induced metabolic syndrome using a rat model. Male Wistar rats were fed a high-fructose $(65 \%)$ diet or standard chow for 1 week, and treated with an ethyl acetate (EtOAc) extract of amla, a polyphenol-rich fraction, at 10 or $20 \mathrm{mg} / \mathrm{kg}$ body weight per d, or vehicle, for 2 weeks. Serum glucose, TAG, total cholesterol and blood pressure levels of the high-fructose diet-fed rats were increased compared with those of the normal rats $(P<0 \cdot 001)$. However, the EtOAc extract of amla ameliorated the high fructoseinduced metabolic syndrome, including hypertriacylglycerolaemia and hypercholesterolaemia. Also, the elevated levels of hepatic TAG and total cholesterol in rats given the high-fructose diet were significantly reduced by 33.8 and $24.6 \%$, respectively $(P<0.001)$, on the administration of the EtOAc extract of amla at the dose of $20 \mathrm{mg} / \mathrm{kg}$ with the regulation of sterol regulatory element-binding protein (SREBP)-1 expression. The protein levels of PPAR $\alpha$ and SREBP-2 were not affected by the feeding of the high-fructose diet or EtOAc extract of amla. In addition, oral administration of the amla extract at the dose of $20 \mathrm{mg} / \mathrm{kg}$ significantly inhibited the increased serum and hepatic mitochondrial thiobarbituric acid-reactive substance levels $(21.1$ and $43.1 \%$, respectively; $P<0.001)$. Furthermore, the amla extract inhibited the increase of cyclo-oxygenase- 2 with the regulation of NF- $\mathrm{KB}$ and bcl-2 proteins in the liver, while the elevated expression level of bax was significantly decreased by 8.5 and $10 \cdot 2 \%$ at the doses of 10 and $20 \mathrm{mg} / \mathrm{kg}$ body weight per d, respectively. These findings suggest that fructose-induced metabolic syndrome is attenuated by the polyphenol-rich fraction of amla.

Amla: High-fructose diet: Metabolic syndrome: Sterol regulatory element-binding protein-1: NF-кB

The incidence of the metabolic syndrome characterised by insulin resistance, dyslipidaemia and hypertension is increasing worldwide. This is also associated with increased morbidity and mortality from several prevalent diseases, such as diabetes, cancer, myocardial infarction and stroke. Recent findings have shown that dietary fructose facilitates metabolic derangement and induces oxidative damage ${ }^{(1-5)}$. Also, numerous studies suggest that increased fructose consumption may be an important contributor to the metabolic syndrome ${ }^{(6-12)}$. In addition, a high-fructose diet leads to a well-characterised metabolic syndrome, typically resulting in hyperinsulinaemia, insulin resistance, hypertension, hypertriacylglycerolaemia, dyslipidaemia and a decline in the level of HDL-cholesterol ${ }^{(13,14)}$. Also, high-fructose diet-fed animals have been shown to exhibit altered lipid metabolism due to hepatic stress as a result of the burden of fructose metabolism ${ }^{(3)}$. Recently, functional foods which possess antioxidant activity have attracted attention as agents possibly reducing the risk of the metabolic syndrome induced by a high-fructose diet ${ }^{(15-21)}$.

Emblica officinalis Gaertn., commonly known as amla, is a member of the small genus of Emblica (Euphorbiaceae).
It grows in tropical and subtropical parts of China, India, Indonesia and the Malay Peninsula. It is an important dietary source of vitamin $\mathrm{C}$, minerals and amino acids, and also contains phenolic compounds, tannins, phyllembelic acid, phyllemblin, rutin, curcuminoides and emblicol. All parts of the plant are used for medicinal purposes. Especially, the fruit has been used in Ayurveda as a potent rasayana ${ }^{(22)}$ and traditional medicine for the treatment of diarrhoea, jaundice and inflammation ${ }^{(23)}$. In addition, the pulp of the fruit is smeared on the head to alleviate headaches and dizziness ${ }^{(24)}$. Recently, amla extract has been tested for various pharmacological activities. The fruit extract was reported to exhibit hypolipidaemic $^{(25)}$, antidiabetic ${ }^{(26)}$ and anti-inflammatory activities $^{(27)}$ and inhibit retroviruses such as HIV-1 ${ }^{(28)}$, tumour development ${ }^{(29)}$ and gastric ulcer ${ }^{(30)}$. Moreover, amla extract has been shown to exhibit antioxidant properties ${ }^{(31,32)}$, and it has been reported that the aqueous extract of amla is a potent inhibitor of lipid peroxide formation and a scavenger of hydroxyl and superoxide radicals in vitro ${ }^{(33)}$. In a previous study, we demonstrated the antioxidative property of amla using $\mathrm{Cu}^{2+}$-induced oxidised human $\mathrm{LDL}^{(34)}$. Also, we

Abbreviations: BW, body weight; COX-2, cyclo-oxygenase-2; EtOAc, ethyl acetate; IDL, intermediate-density lipoprotein; I-кB $\alpha$, inhibitor binding protein $\kappa \mathrm{B}-\alpha$; iNOS, inducible NO synthase; SREBP, sterol regulatory element-binding protein; TBA, thiobarbituric acid; Tris, 2-amino-2-hydroxymethyl-1,3-propanediol. * Corresponding author: Dr Takako Yokozawa, fax +81 76434 5068, email yokozawa@inm.u-toyama.ac.jp 
showed that amla, especially an ethyl acetate (EtOAc) extract of amla (a polyphenol-rich fraction), attenuates age-related hyperlipidaemia and renal dysfunction by oxidative stress $^{(35,36)}$. On the basis of these studies, the present study was carried out to evaluate the effect of the polyphenol-rich fraction of amla on fructose-induced metabolic syndrome, and we also determined its related protein expression in a rat model.

\section{Materials and methods \\ Preparation of ethyl acetate extract of amla}

The EtOAc extract was prepared by extracting the air-dried amla fruit pieces in water-EtOAc (1:4) at room temperature for $24 \mathrm{~h}$. The extract was evaporated under a reduced pressure followed by lyophilisation. The yield was $12 \%$ from the dried fruit pieces.

\section{Total polyphenol and vitamin $C$ contents of ethyl acetate} extract

The total polyphenol content of the EtOAc extract of amla was measured by employing a colorimetric method using gallic acid as a standard. The vitamin $\mathrm{C}$ content was measured using HPLC.

\section{HPLC analysis of polyphenol components in ethyl acetate extract}

An HPLC system (Waters Co., Milford, MA, USA) was used for the analysis of the polyphenol components of the EtOAc extract. Samples were analysed using the reverse-phase column C18 Cosmosil AR II $(25 \times 0.4 \mathrm{~cm}$, particle size $5 \mu \mathrm{m}$; Nakalai Tesque Inc., Kyoto, Japan) using $50 \mathrm{~mm}$-phosphoric acid (A) and $\mathrm{CH}_{3} \mathrm{CN}$ (B) as a solvent at a flow rate of $0.8 \mathrm{ml} / \mathrm{min}$. The gradient used was $5 \% \mathrm{~B}$ in A solvent to reach $30 \% \mathrm{~B}$ during the first $39 \mathrm{~min}$, and $75 \% \mathrm{~B}$ in $\mathrm{A}$ solvent at $54 \mathrm{~min}$. Chromatograms were detected at $280 \mathrm{~nm} \mathrm{UV.}$

\section{Animals and treatment}

All surgical and experimental procedures were performed in accordance with the recommendations found in the Guide for the Care and Use of Laboratory Animals ${ }^{(37)}$ and approved by the Institutional Animal Care and Use Committee of the University of Toyama. Wistar male rats (Japan SLC Inc., Hamamatsu, Japan) were maintained with water and food ad libitum at a constant humidity and temperature, with a light-dark cycle of $12 \mathrm{~h}$. After adaptation for $7 \mathrm{~d}$, the rats (average weight 217 (SE 6) g) were randomised into four groups composed of eight rats each: a normal diet group, a high-fructose diet-fed group, and two groups supplemented with a $65 \%$ high-fructose diet and administered the EtOAc extract of amla at 10 or $20 \mathrm{mg} / \mathrm{kg}$ body weight (BW) per d via oral administration. The high-fructose diet (Table 1) was supplied for 2 weeks. During the experimental period, consumption of diet was kept at the same level ( $16 \mathrm{~g} / \mathrm{d}$ per rat). Rats consumed the same amount of fructose regardless of the treatment, and no significant differences in BW or the daily intake of fructose were observed between treatment groups. At the end of the study, blood was collected and
Table 1. Composition of the diets $(\mathrm{g} / 100 \mathrm{~g})$

\begin{tabular}{lcc}
\hline Ingredients & Normal diet & High-fructose diet \\
\hline Casein & 20 & 20 \\
Maize starch & 65 & - \\
Fructose & - & 65 \\
Maize oil & 5 & 5 \\
Salt mixture & 4 & 4 \\
Vitamin mixture & 1 & 1 \\
Cellulose powder & 4.5 & 4.5 \\
DL-Methionine & 0.3 & 0.3 \\
Choline bitartrate & 0.2 & 0.2
\end{tabular}

the serum was separated by centrifuging the blood at $1000 \mathrm{~g}$ for $15 \mathrm{~min}$ at $4^{\circ} \mathrm{C}$. After collecting blood samples, liver and epididymal fat tissues were excised immediately, weighed, and frozen in liquid $\mathrm{N}_{2}$. All serum and tissue samples were stored at $-80^{\circ} \mathrm{C}$ until use for the determination of biochemical markers.

\section{Blood sample preparation and analyses}

The serum glucose and total cholesterol levels were determined using commercial reagents (Glucose CII-Test Wako and Cholesterol E-Test Wako, respectively; Wako Pure Chemical Industries, Ltd, Osaka, Japan). Lipoproteins were isolated from serum using density-gradient ultracentrifugation, as described by Havel et al. ${ }^{(38)}$. Lipoprotein fractions were isolated from $4 \mathrm{ml}$ serum using a Beckman Optima XL-70 ultracentrifuge and a 70.1 $\mathrm{Ti}$ rotor operating at $160000 \mathrm{~g}$. Serum was transferred to tubes, and the density was adjusted to $1.006,1.019$ and $1.063 \mathrm{~g} / \mathrm{ml}$ with the same volume of $\mathrm{KBr}$ solution. Serum was divided into three lipoprotein classes by density: VLDL ( $d$ 1.006); intermediate-density lipoprotein (IDL; $1.006<d<1.019) ;$ LDL $(1.019<d<1.603)$. The appropriate times were calculated to be $16 \mathrm{~h}$ for VLDL, $18 \mathrm{~h}$ for IDL and $20 \mathrm{~h}$ for LDL isolation at $4^{\circ} \mathrm{C}$. TAG levels in serum and lipoprotein fractions were determined using a commercial reagent (Triglyceride E-Test Wako; Wako Pure Chemical Industries, Ltd, Osaka, Japan). Serum glycated protein and thiobarbituric acid (TBA)-reactive substance levels were measured using the methods of McFarland et al. ${ }^{(39)}$ and Naito \& Yamanaka ${ }^{(40)}$, respectively.

\section{Measurement of hepatic TAG and total cholesterol contents}

The liver of each rat was homogenised, total lipids were extracted with a mixture of chloroform and methanol (2:1, $\mathrm{v} / \mathrm{v})$ according to the method of Folch et al. ${ }^{(41)}$, and the contents of TAG and total cholesterol were determined using the Wako kits described above.

\section{Measurement of blood pressure}

At the end of the experiment, blood pressure was measured by the tail-cuff method using an automatic blood pressure monitoring system (UR-5000; UETA, Tokyo, Japan). The animals were kept at $37^{\circ} \mathrm{C}$ for 30 min before measurements were performed. The average of five consecutive readings was used for blood pressure evaluation. 
Isolation of hepatic mitochondria and measurement of thiobarbituric acid-reactive substance levels

The liver was homogenised with a nine-fold volume of ice-cold $0.9 \% \mathrm{NaCl}$ solution. Mitochondria were prepared from hepatic homogenates by differential centrifugation ( $800 \mathrm{~g}$ and $12000 \mathrm{~g} ; 4^{\circ} \mathrm{C} ; 15 \mathrm{~min}$ ) according to the methods of Johnson \& Lardy ${ }^{(42)}$ and Jung \& Pergande ${ }^{(43)}$, respectively, with slight modifications. Each pellet was re-suspended in preparation medium, and the TBA-reactive substance concentration was determined by the method of Buege \& Aust ${ }^{(44)}$. Briefly, $250 \mu \mathrm{l}$ of each re-suspended pellet or working standard was added to $750 \mu \mathrm{l}$ of TBA-TCA-HCl solution $(0.4 \%$ of TBA, $15 \%$ of TCA and $2.5 \% \mathrm{HCl})$ and it was heated at $95-100^{\circ} \mathrm{C}$ for $20 \mathrm{~min}$ and cooled in an ice-bath. Then, samples were centrifuged at $1000 \mathrm{~g}$ at room temperature for $10 \mathrm{~min}$ to transfer supernatant fractions from the denatured protein precipitate. The TBA-reactive substance level was determined by measuring the absorbance at $532 \mathrm{~nm}$. This was expressed in nmol malondialdehyde (MDA)/mg protein using a calibration curve constructed from MDA $(0-25 \mathrm{nmol} / \mathrm{ml})$ in 1,1,3,3-tetramethoxypropane. The protein level was evaluated by the method of Itzhaki \& Gill ${ }^{(45)}$ with bovine serum albumin as the standard.

\section{Homogenisation, isolation of cytosol and nuclear extracts}

Each liver was homogenised by a Potter Elvehjem homogeniser in 4 volumes (w/v) of buffer A containing $25 \mathrm{~mm}$ 2-amino-2-hydroxymethyl-1,3-propanediol (Tris)- $\mathrm{HCl}$ ( $\mathrm{pH} \mathrm{7.5),}$ $250 \mathrm{~mm}-\mathrm{NaCl}, 5 \mathrm{~mm}-\mathrm{EDTA}, 1 \mathrm{mM}-$ phenylmethylsulfonyl fluoride, $1 \mathrm{~mm}$-dithiothreitol and a mixture of protease inhibitors (100 mM-4-(2-aminoethyl)benzenesulfonyl fluoride, $0.08 \mathrm{~mm}$ aprotinin, $2 \mathrm{~mm}$-leupeptin, $5 \mathrm{~mm}$-bestatin, $1 \mathrm{mM}$-pepstatin A and $1.5 \mathrm{~mm}-\mathrm{E}-64)$. Homogenates were incubated for $15 \mathrm{~min}$ on ice, $10 \%$ Nonidet P-40 was added, and then they were centrifuged at $4000 \mathrm{~g}$ at $4^{\circ} \mathrm{C}$, for $5 \mathrm{~min}$. Supernatant fractions were used for inducible NO synthase (iNOS), cyclo-oxygenase-2 (COX-2), bax and bcl-2 protein determination. Nuclear extracts were isolated using the method of Sakurai et al. ${ }^{(46)}$. Briefly, liver was homogenised by a Potter Elvehjem homogeniser in 4 volumes $(\mathrm{w} / \mathrm{v})$ of buffer A containing $10 \mathrm{~mm}-\mathrm{HEPES}$ (pH 7.9), $10 \mathrm{~mm}-\mathrm{KCl}, 0 \cdot 1 \mathrm{~mm}$-EDTA, $1 \mathrm{~mm}-$ dithiothreitol, $0.5 \mathrm{~mm}$-phenylmethylsulfonyl fluoride and protease inhibitors as above. Homogenates were incubated for 15 min on ice, $10 \%$ Nonidet P-40 was added, and then they were centrifuged at $4000 \mathrm{~g}$ at $4^{\circ} \mathrm{C}$ for $5 \mathrm{~min}$. Supernatant fractions were used for inhibitor binding protein $\kappa \mathrm{B}-\alpha(\mathrm{I}-\kappa \mathrm{B} \alpha)$ protein determination, and pellets were re-suspended in 2 volumes of buffer B containing $20 \mathrm{mM}-\mathrm{HEPES}$ ( $\mathrm{pH} 7 \cdot 9$ ), $0 \cdot 4 \mathrm{M}-\mathrm{NaCl}, 1 \mathrm{mM}$-EDTA, $1 \mathrm{~mm}$-dithiothreitol, $1 \mathrm{mM}$-phenylmethylsulfonyl fluoride and the protease inhibitors. Homogenates were kept for $15 \mathrm{~min}$ at $4^{\circ} \mathrm{C}$ and then centrifuged at $14000 \mathrm{~g}$ for $5 \mathrm{~min}$ at $4^{\circ} \mathrm{C}$. Supernatant fractions were collected in microcentrifuge tubes, and used for $\operatorname{PPAR} \alpha$, sterol regulatory element-binding protein (SREBP)-1/2 and NF- $\mathrm{BB}$ protein determination. The protein concentration of homogenates and nuclear extracts was determined by the Bio-Rad protein assay (Bio-Rad Laboratories, Hercules, CA, USA). Each sample (30 $\mu \mathrm{g}$ protein/lane) was denatured by boiling in Laemmli sample buffer and stored at $-80^{\circ} \mathrm{C}$ until the assay ${ }^{(47)}$.

\section{Western blot analyses}

Homogenates (30 $\mu \mathrm{g}$ for iNOS, COX-2, bax and bcl-2), cytosol extract ( $30 \mu \mathrm{g}$ for $\mathrm{I}-\kappa \mathrm{B} \alpha)$ and crude nuclear extracts $(30 \mu \mathrm{g}$ for PPAR $\alpha$, SREBP-1/2 and NF-кB) from the liver were subjected to SDS-PAGE $(10 \%, \mathrm{w} / \mathrm{v})$. The separated proteins were blotted onto nitrocellulose (Bio-Rad, Hercules, CA, USA). Blots were blocked overnight at $4^{\circ} \mathrm{C}$ with $5 \%$ non-fat dry milk in TBS-T (25 mM-Tris-HCl (pH 8.3), $140 \mathrm{~mm}-\mathrm{NaCl}$, $2 \mathrm{mM}-\mathrm{KCl}$ and $0.1 \%$ Tween 20). Membranes were then incubated for $3 \mathrm{~h}$ at $4^{\circ} \mathrm{C}$ with the primary polyclonal antibodies raised against $\mathrm{NF}-\kappa \mathrm{B}, \mathrm{I}-\kappa \mathrm{B} \alpha$, bax, PPAR $\alpha$ and SREBP-1/2 (dilution, 1:1000), and monoclonal antibodies against iNOS,

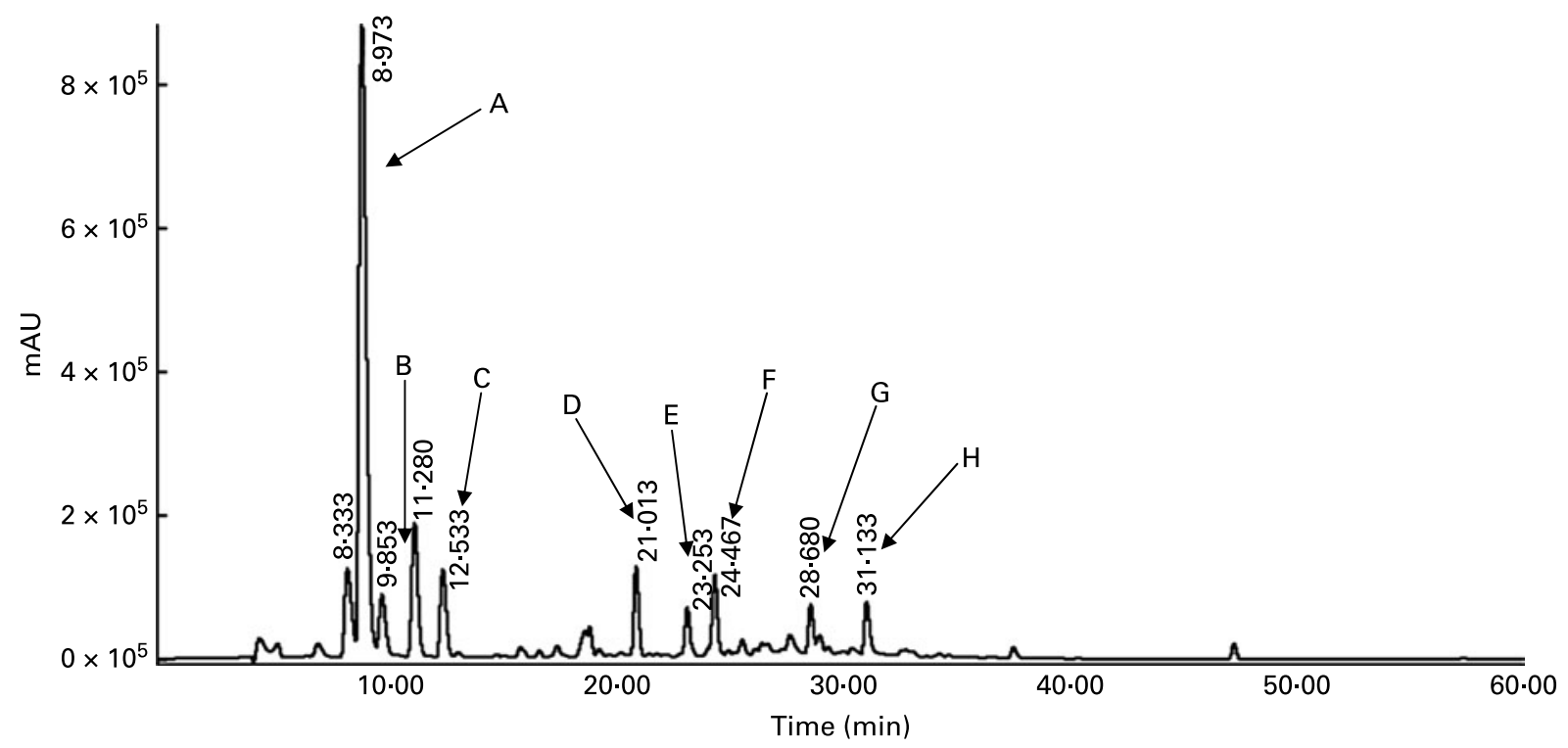

Fig. 1. HPLC analysis of polyphenol components in an ethyl acetate extract of amla (Emblica officinalis Gaertn.). Peaks: A, gallic acid; B, mucic acid 1,4-lactone 3-O-gallate; C, mucic acid 1,4-lactone 2-O-gallate; D, furosin; E, corilagin; F, geraniin; $\mathrm{G}$, chebulagic acid; $\mathrm{H}$, ellagic acid. mAU, milli arbitrary units. 
COX-2, bcl-2 (dilution, 1:1000) and $\beta$-actin (1:5000) (antibodies from Santa Cruz Biotechnology, Santa Cruz, CA, USA). After extensive washing, incubation with the second antibody (rabbit polyclonal or mouse monoclonal antibody) at a dilution of 1:1000 (Santa Cruz Biotechnology) was also performed for $40 \mathrm{~min}$ at room temperature. Specific protein was detected by enhanced chemiluminescence (ECL; Amersham International, Little Chalfont, Bucks, UK) and quantified with a Phosphor Imager (Bio-Rad Laboratories, Hercules, CA, USA). Band densities were determined using ATTO Densitograph Software (ATTO Corporation, Tokyo, Japan) and quantified as the ratio to $\beta$-actin. These protein levels of groups were expressed relative to those of normal diet-fed rats.

\section{Statistical analysis}

The results are expressed as mean values with their standard errors. The effect on each parameter was examined using one-way ANOVA. Individual differences between groups were evaluated using Dunnett's test, and those at $P<0.05$ were considered significant.

\section{Results}

\section{Total polyphenol and vitamin $C$ contents of ethyl acetate extract}

The total polyphenol content of the EtOAc extract was $80 \cdot 4$ (SE 4.3) \%; however, vitamin $\mathrm{C}$ was not in the present extract.

\section{Polyphenol components of ethyl acetate extract}

Chromatograms of the EtOAc extract of amla are shown in Fig. 1. Major components were gallic acid (peak A), ellagic acid (peak H) and ellagitannins. Ellagitannins comprised three compounds: corilagin, geraniin and chebulagic acid (peaks E, F and G, respectively). Components of polyphenol compounds in the EtOAc extract were $5.847 \%$ gallic acid, $1.187 \%$ corilagin, $4.303 \%$ geraniin, $5.547 \%$ chebulagic acid and $1.603 \%$ ellagic acid. Furthermore, several peaks besides the above components were detected; that is, mucic acid mono- and di-gallate, and the mixtures including their isomers (eluted before peak A) were as follows: mucic acid 1,4-lactone 3-O-gallate (peak $\mathrm{B}$ ), mucic acid 1,4-lactone 2-O-gallate (peak C) and furosin (peak D), as reported by Zhang et al. ${ }^{(48)}$.

\section{Characteristics of experimental animals}

As shown in Table 2, the BW of the high-fructose diet-fed control rats (241.0 (SE 4.0) g) was higher than that of the normal diet-fed rats (231.8 (SE 9.2) g), but this was slightly decreased by the oral administration of the EtOAc extract of amla. Compared with the normal diet-fed rats, the absolute and relative liver weights were significantly increased in the high fructose-fed control rats $(P<0 \cdot 001)$. The EtOAc extract of amla suppressed the increase in the liver weight. The weight of the epididymal fat pads was significantly higher in the high fructose-fed control rats $(P<0 \cdot 001)$ as compared with the normal diet-fed rats, while their weight in the EtOAc extract of amla-fed group significantly decreased compared with the high fructose-fed control rats. Daily fluid intake was not affected by the high-fructose diet. Also, the high-fructose diet consumed over 2 weeks significantly increased the levels of serum glucose (54.5\%;P<0.001) and total cholesterol (34.6\%; $P<0.001)$. The level of serum glucose led to a tendency toward a decrease, and the level of serum total cholesterol significantly decreased through the administration of the EtOAc extract of amla $(P<0.01)$. In addition, TAG levels in the serum, and the VLDL, IDL and LDL fractions markedly increased with the

Table 2. Characteristics of experimental animals

(Mean values with their standard errors for eight animals per group)

\begin{tabular}{|c|c|c|c|c|c|c|c|c|}
\hline & \multicolumn{2}{|c|}{ Normal diet } & \multicolumn{2}{|c|}{ High-fructose diet } & \multicolumn{2}{|c|}{$\begin{array}{c}\text { EtOAc extract } \\
(10 \mathrm{mg} / \mathrm{kg} \mathrm{BW}) \ddagger\end{array}$} & \multicolumn{2}{|c|}{$\begin{array}{c}\text { EtOAc extract } \\
(20 \mathrm{mg} / \mathrm{kg} \mathrm{BW}) \ddagger\end{array}$} \\
\hline & Mean & SE & Mean & SE & Mean & SE & Mean & SE \\
\hline BW (g) & $231 \cdot 8$ & $9 \cdot 2$ & $241 \cdot 0^{*}$ & $4 \cdot 0$ & 233.0† & 2.9 & $235 \cdot 1$ & $1 \cdot 2$ \\
\hline Weight of liver $(\mathrm{g})$ & $7 \cdot 23$ & $0 \cdot 21$ & $10 \cdot 52^{* * *}$ & 0.50 & $9 \cdot 49^{* * *}+\dagger \dagger$ & 0.29 & $9 \cdot 37^{* * *}+\dagger \dagger$ & 0.22 \\
\hline $\begin{array}{l}\text { Relative weight of liver } \\
(\mathrm{g} / 100 \mathrm{~g} \mathrm{BW})\end{array}$ & $3 \cdot 13$ & $0 \cdot 21$ & $4 \cdot 34^{\star \star \star}$ & 0.23 & $4 \cdot 08^{\star \star \star}$ & $0 \cdot 13$ & $3 \cdot 93^{\star \star \star}+\dagger$ & 0.07 \\
\hline Weight of epididymal fat pads (g) & $2 \cdot 32$ & $0 \cdot 10$ & $2 \cdot 66^{\star \star \star}$ & 0.11 & $2 \cdot 38 † \dagger$ & 0.11 & 2.30††† & 0.12 \\
\hline $\begin{array}{l}\text { Relative weight of epididymal fat } \\
\text { pads }(\mathrm{g} / 100 \mathrm{~g} \mathrm{BW})\end{array}$ & 1.01 & $0 \cdot 11$ & $1 \cdot 13$ & 0.04 & $0.93+† \dagger$ & 0.06 & $0.90 \dagger \dagger \dagger$ & $0 \cdot 10$ \\
\hline Fluid intake (ml/rat per d) & $26 \cdot 0$ & 0.8 & $26 \cdot 9$ & 0.7 & $27 \cdot 8$ & 0.6 & $27 \cdot 0$ & 0.7 \\
\hline Glucose (mg/l) & 1366 & 17 & $2111^{\star \star \star}$ & 42 & $2076^{\star \star *}$ & 23 & $1995^{\star * *}$ & 45 \\
\hline Total cholesterol (mg/l) & 609 & 26 & $820^{\star \star \star}$ & 35 & $745^{\star \star \star}+\dagger$ & 38 & $743^{\star \star \star} \dagger †$ & 19 \\
\hline $\mathrm{TAG}(\mathrm{mg} / \mathrm{l})$ & 451 & 41 & $2442^{\star \star \star}$ & 379 & $1482^{\star \star \star} † \dagger † ~$ & 147 & 875††† & 85 \\
\hline VLDL-TAG (mg/l) & 223 & 7 & $1778^{\star \star \star}$ & 2 & $933^{\star \star \star}+† \dagger$ & 5 & $719^{\star \star \star}$ ††† & 0 \\
\hline IDL-TAG (mg/l) & 64 & 5 & $212^{\star \star \star}$ & 0 & $171^{\star * *}+\dagger \dagger$ & 5 & $175^{\star \star \star}+† \dagger$ & 0 \\
\hline LDL-TAG $(\mathrm{mg} / \mathrm{l})$ & 3 & 0 & $51^{\star \star \star}$ & 3 & $41^{\star \star *} † \dagger \dagger$ & 3 & $38^{\star \star *} \dagger \dagger \dagger$ & 0 \\
\hline Systolic blood pressure (mmHg) & $114 \cdot 0$ & 1.0 & $127 \cdot 8^{\star \star \star}$ & $2 \cdot 2$ & 119.0††† & $5 \cdot 6$ & $113 \cdot 8 \dagger+\dagger$ & $4 \cdot 3$ \\
\hline Diastolic blood pressure $(\mathrm{mmHg})$ & $56 \cdot 8$ & $4 \cdot 6$ & $73 \cdot 3^{\star \star}$ & 5.9 & $67 \cdot 7 \dagger$ & $5 \cdot 8$ & $66 \cdot 1^{\star \star}$ & $3 \cdot 2$ \\
\hline Heart rate (beats/min) & $487 \cdot 4$ & $8 \cdot 2$ & $488 \cdot 9$ & $6 \cdot 6$ & $515 \cdot 6^{\star \star}+\dagger$ & $12 \cdot 2$ & $518 \cdot 5^{\star \star}+\dagger †$ & $12 \cdot 8$ \\
\hline
\end{tabular}

EtOAc, ethyl acetate; BW, body weight; IDL, intermediate-density lipoprotein.

Mean value was significantly different from that of the normal diet-fed rats: ${ }^{*} P<0.05,{ }^{\star *} P<0.01,{ }^{\star * \star} P<0.001$.

Mean value was significantly different from that of the high-fructose diet-fed control rats: $\dagger P<0.05, \dagger \dagger P<0.01, \dagger \dagger \dagger P<0.001$.

$\ddagger$ EtOAc extract of amla (Emblica officinalis Gaertn.). 

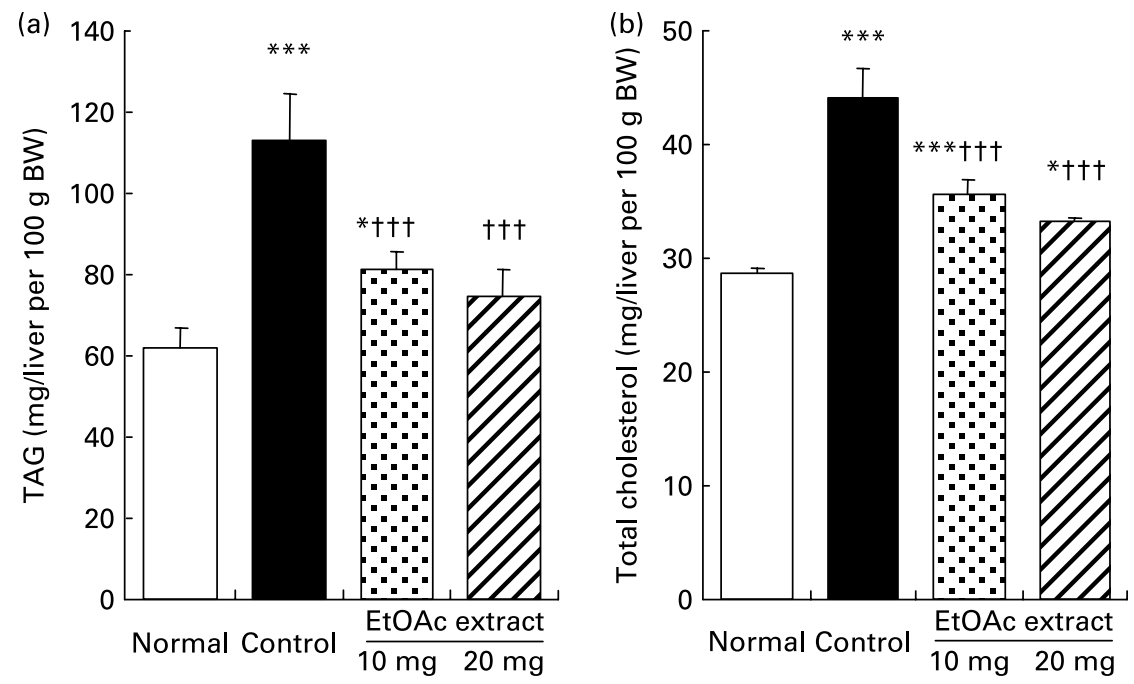

Fig. 2. Hepatic TAG (a) and total cholesterol (b) contents of rats fed a normal diet, a control high-fructose diet or a high-fructose diet supplemented with an ethyl acetate extract (EtOAc extract) of amla (Emblica officinalis Gaertn.), at 10 or $20 \mathrm{mg} / \mathrm{kg}$ body weight. Values are means for eight rats per group, with standard errors represented by vertical bars. Mean value was significantly different from that of the normal diet-fed rats: ${ }^{\star} P<0.05,{ }^{\star \star \star} P<0.001$. $\dagger+\dagger$ Mean value was significantly different from that of the high-fructose diet-fed control rats $(P<0.001)$.

high-fructose diet $(P<0 \cdot 001)$. The elevated levels were significantly and dose-dependently lowered by the EtOAc extract of amla. Systolic blood pressure was significantly higher in the high fructose-fed rats than in the normal rats (127.8 (SE 2.2) v. 114.0 (SE 1.0) $\mathrm{mmHg}$, respectively; $P<0.001)$ and was effectively controlled by the EtOAc extract of amla.

\section{Lipid contents and protein (PPAR $\alpha$ and sterol regulatory} element-binding protein-1/2) levels in the liver

As shown in Fig. 2, the hepatic TAG contents in the fructosefed control rats increased by $1 \cdot 8$-fold compared with the normal rats (109.9 (SE 11.4) v. 60.0 (SE 5.2) mg/liver per $100 \mathrm{~g} \mathrm{BW}$, respectively; $P<0.001)$. The hepatic TAG contents were significantly lowered in the EtOAc extract of amla-fed rats at the oral doses of 10 and $20 \mathrm{mg} / \mathrm{kg}$ BW per d compared with the high fructose-fed control rats by $28 \cdot 1$ and $33.8 \%$, respectively $(P<0.001)$. Also, the hepatic total cholesterol level of the high fructose-fed control rats increased 1.5-fold compared with the normal rats. However, the administration of the EtOAc extract of amla at the doses of 10 and $20 \mathrm{mg}$ significantly decreased the hepatic total cholesterol levels by 19.1 and $24.6 \%$, respectively $(P<0 \cdot 001)$. Moreover, SREBP-1 protein levels in the high
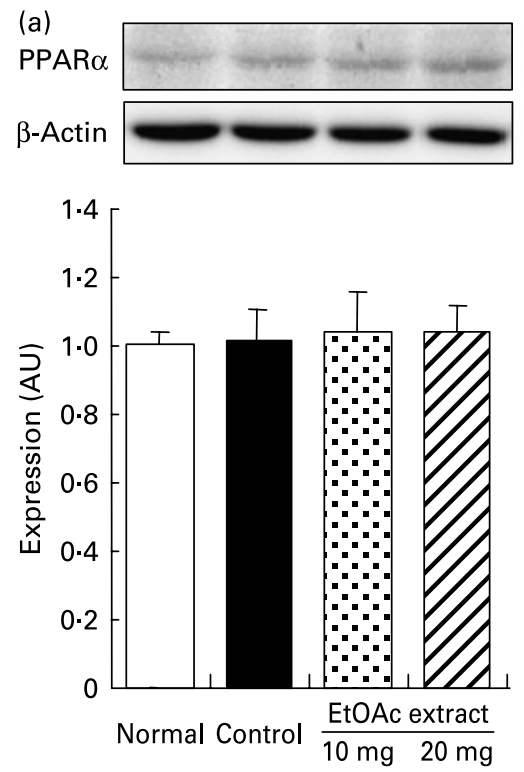

(b)
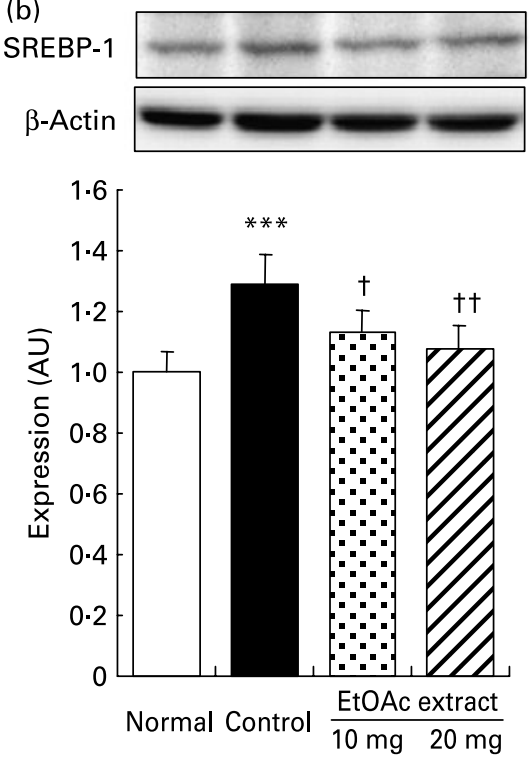

(c)
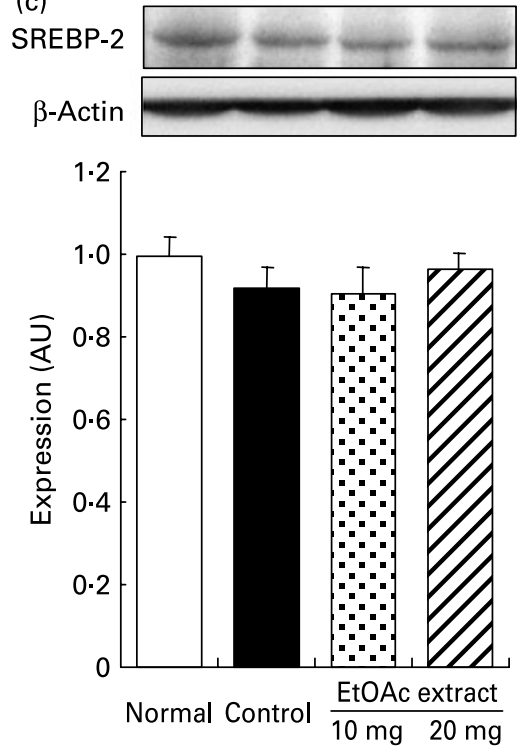

Fig. 3. Western blot analysis of expressions of PPAR $\alpha$ (a), sterol regulatory element-binding protein (SREBP)-1 (b) and SREBP-2 (c) in the liver of rats fed a normal diet, a control high-fructose diet or a high-fructose diet supplemented with an ethyl acetate extract (EtOAc extract) of amla (Emblica officinalis Gaertn.), at 10 or $20 \mathrm{mg} / \mathrm{kg}$ body weight. AU, arbitrary units. Values are means for eight rats per group, with standard errors represented by vertical bars. ${ }^{* \star \star}$ Mean value was significantly different from that of the normal diet-fed rats $(P<0.001)$. Mean value was significantly different from that of the high-fructose diet-fed control rats: † $P<0.05$, †† $P<0.01$. 

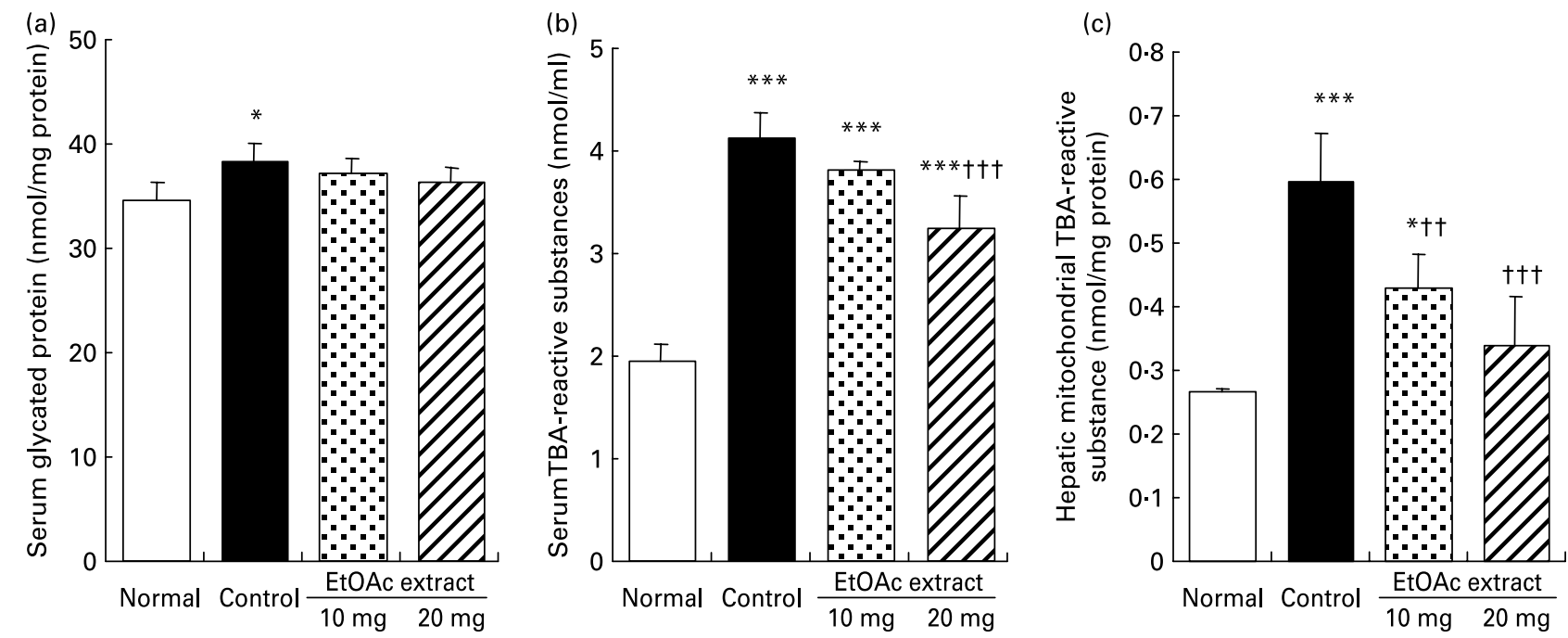

Fig. 4. Serum glycated protein (a), serum thiobarbituric acid (TBA)-reactive substance levels (b) and hepatic mitochondrial TBA-reactive substance levels (c) of rats fed a normal diet, a control high-fructose diet or a high-fructose diet supplemented with an ethyl acetate extract (EtOAc extract) of amla (Emblica officinalis Gaertn.), at 10 or $20 \mathrm{mg} / \mathrm{kg}$ body weight. Values are means for eight rats per group, with standard errors represented by vertical bars. Mean value was significantly different from that of the normal diet-fed rats: ${ }^{\star} P<0.05$, ${ }^{\star \star *} P<0.001$. Mean value was significantly different from that of the high-fructose diet-fed control rats: †† $P<0.01$, †† $P<0.001$.

fructose-fed control rats significantly increased 1.3-fold compared with the normal rats $(P<0 \cdot 001)$. The oral administration of the EtOAc extract of amla at the doses of 10 and $20 \mathrm{mg} / \mathrm{kg}$ BW per d significantly decreased the level of SREBP-1 protein in the nuclei of the liver by 12.4 and $16 \cdot 3 \%$ compared with the high fructose-fed control rats, respectively. There was no significant difference in the protein levels of PPAR $\alpha$ and SREBP-2 in the nuclei of the liver between the experimental groups (Fig. 3).

\section{Glycated protein and thiobarbituric acid-reactive substance levels in the serum and hepatic mitochondria}

As shown in Fig. 4, the serum glycated protein level of the high fructose-fed control rats was higher than that of the normal diet-fed rats (38.3 (SE 1.8) v. 34.5 (SE 1.8) nmol/mg protein, respectively; $P<0 \cdot 05)$. However, it was not affected by the EtOAc extract of amla. Furthermore, the TBA-reactive substance levels of serum were significantly higher in the high fructose-fed control rats than those in the normal diet-fed rats (4.1 (SE 0.3) v. $1.9(\mathrm{SE} \mathrm{0.2)} \mathrm{nmol} / \mathrm{ml}$, respectively; $P<0.001)$. However, the administration of the EtOAc extract of amla at the dose of $20 \mathrm{mg} / \mathrm{kg}$ led to a significantly lower TBA-reactive substance level of serum, being $21.1 \%$ lower than that in the fructose-fed control rats. Also, TBA-reactive substance levels of hepatic mitochondria were significantly lower in the EtOAc extract of amla-fed rats $(43.1 \% ; P<0.001)$ than in the fructose-fed control rats.

\section{Protein levels involved in the pro-inflammatory state of the liver}

Protein levels involved in the pro-inflammatory state of the liver in the high fructose-fed rats were examined by Western blot analysis (Fig. 5). The protein levels of hepatic NF-кB were significantly lower in the EtOAc extract of amla-fed rats than in the high fructose-fed control rats. However, there was no significant difference between the groups regarding the hepatic I- $\kappa \mathrm{B} \alpha$ and iNOS protein levels. The protein level of COX-2 in the liver was 24.4 and $26.0 \%$ lower in the EtOAc extract of amla-fed rats than in the high fructosefed control rats at the doses of 10 and $20 \mathrm{mg}$, respectively. Also, the bax protein level in the high-fructose diet-fed rats significantly increased by $18.0 \%$ compared with the normal diet-fed rats $(P<0 \cdot 01)$, whereas the EtOAc extract of amlafed rats showed significant decreases of 8.5 and $10.2 \%$ at the doses of 10 and $20 \mathrm{mg} / \mathrm{kg}$ BW per d, respectively. However, the bcl-2 protein level in the high fructose-fed rats significantly decreased by $21.0 \%$ compared with the normal diet-fed rats $(P<0.001)$, while the oral administration of the EtOAc extract of amla led to significant increases by $19 \cdot 0$ and $24.1 \%$ at the doses of 10 and $20 \mathrm{mg} / \mathrm{kg}$ BW per d, respectively, compared with the fructose-fed control rats.

\section{Discussion}

High-fructose diets have been used in animal models to induce the metabolic syndrome, including abdominal obesity, dyslipidaemia, hypertension, insulin resistance, microalbuminuria, and prothrombotic and pro-inflammatory states ${ }^{(4,5,14,49-52)}$. In addition, high fructose-fed animals exhibit an alternation in lipid metabolism due to hepatic oxidative stress as a result of the burden of fructose metabolism ${ }^{(3)}$. Our present study also showed that a high-fructose diet during 2 weeks induced metabolic alterations such as hyperglycaemia, dyslipidaemia and hypertension. Moreover, the present results showed that a high-fructose diet led to a significant increase in TAG levels in the serum and lipoprotein fractions. These results indicate that a low-fructose diet would play a role in ameliorating pathological conditions such as diabetes and CVD. Therefore, the rat model with fructose-induced metabolic syndrome was used in the present study to investigate the protective role of the polyphenol-rich extract of amla (EtOAc extract of amla) against the metabolic syndrome. 


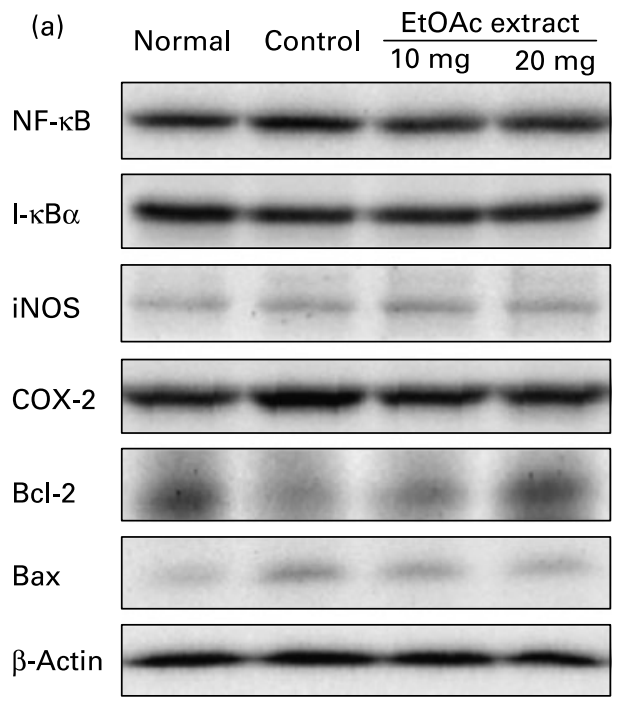

(b)

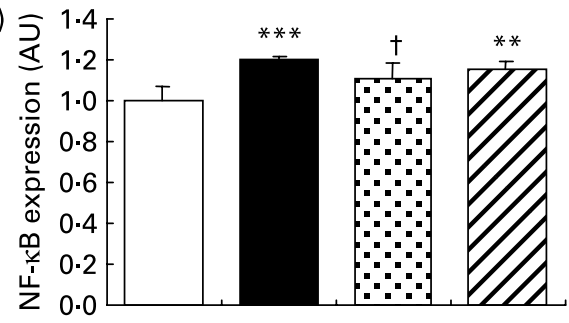

(c)

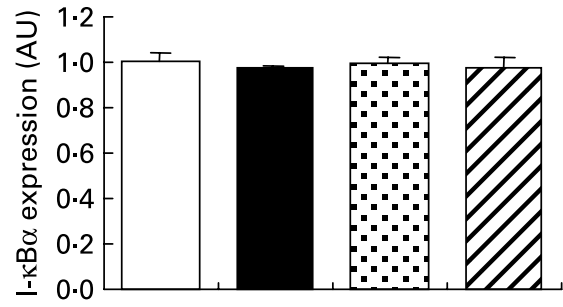

(d)

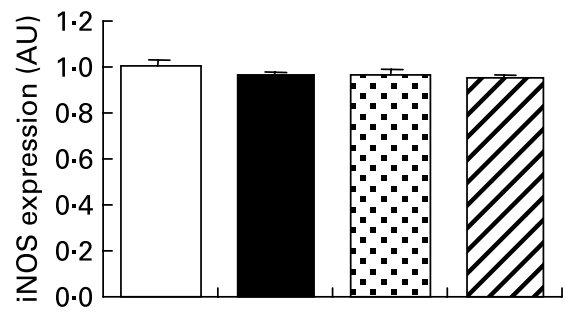

(e)

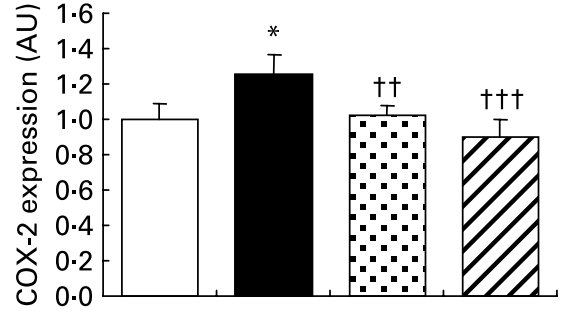

(f)

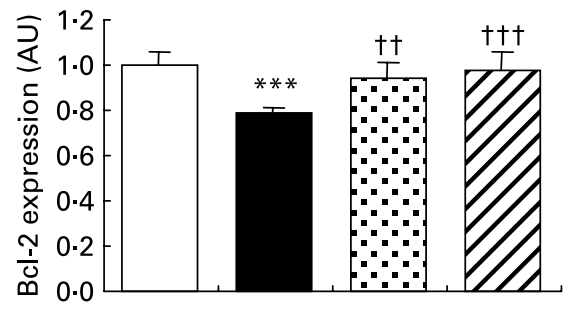

(g)

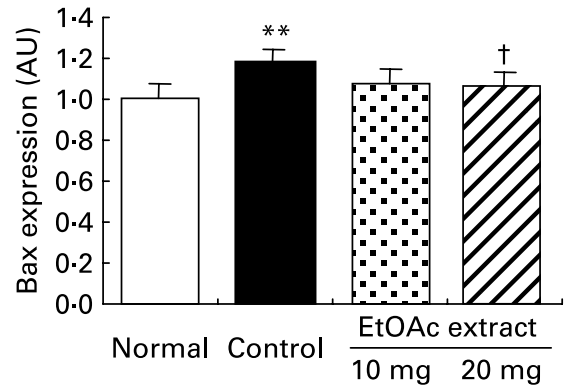

Fig. 5. Western blot (a) analysis of protein expressions involved in the inflammatory status of the liver: NF-кB (b); inhibitor binding protein $\kappa \mathrm{B}-\alpha(\mathrm{l}-\kappa \mathrm{B} \alpha)(\mathrm{c})$; inducible NO synthase (iNOS) (d); cyclo-oxygenase-2 (COX-2) (e); Bcl-2 (f); Bax (g). Rats were fed a normal diet, a control high-fructose diet or a high-fructose diet supplemented with an ethyl acetate extract (EtOAc extract) of amla (Emblica officinalis Gaertn.), at $10 \mathrm{or} 20 \mathrm{mg} / \mathrm{kg}$ body weight. AU, arbitrary units. Values are means for eight rats per group, with standard errors represented by vertical bars. Mean value was significantly different from that of the normal diet-fed rats: ${ }^{*} P<0.05$, ${ }^{\star *} P<0.01,{ }^{\star \star \star} P<0.001$. Mean value was significantly different from that of the high-fructose diet-fed control rats: $\dagger P<0.05, \dagger^{\circ} P<0.01, \dagger \dagger \dagger P<0.001$. 
The EtOAc extract of amla significantly attenuated the increase in liver weight by the high-fructose diet and significantly decreased the weight of epididymal fat pads increased by the diet. Furthermore, the high-fructose diet elevated the serum glucose levels, which may indicate the progression of insulin resistance. The results suggest that the EtOAc extract of amla would probably play a protective role against the abnormal metabolism of carbohydrate induced by a high-fructose diet. In addition, hypertriacylglycerolaemia and TAG-rich lipoproteins are part of a metabolic syndrome frequently encountered in individuals with early-onset $\mathrm{CHD}^{(53)}$. VLDL, the main carrier of TAG, has a well-established indirect atherogenic potency as the precursor of LDL, and may promote the development of atherosclerotic lesions through activation of the pro-inflammatory transcription factor NF$\mathrm{KB}^{(54-56)}$. However, the EtOAc extract of amla reduced TAG levels that had markedly increased in the serum, VLDL, IDL and LDL fractions by the high-fructose diet. These findings imply that the EtOAc extract of amla may reduce the development of atherosclerotic lesions by inhibiting the oxidative modification of VLDL and LDL in the arterial wall.

Moreover, the present results showed that the oral administration of the EtOAc extract of amla ameliorated the increase of hepatic TAG content with the regulation of blood pressure. These results indicate that the EtOAc extract of amla would protect against hypertriacylglycerolaemia and hypertension induced by a high-fructose diet. In addition, it inhibited the increase of total cholesterol level in the liver. Our previous study also demonstrated that amla prevented hypercholesterolaemic atherosclerosis and attenuated the risk of CVD by not only reductions in LDL-cholesterol and its oxidation, but also the decline in lipid peroxidation ${ }^{(34)}$. Based on this evidence, the polyphenol-rich fraction of amla is expected to play a protective role against the metabolic syndrome related to a highfructose diet including hypertriacylglycerolaemia, dyslipidaemia and hypertension.

The $\beta$-oxidation of fatty acids and the synthesis of fatty acids and TAG in the liver are regulated by the nuclear receptors PPAR $\alpha$ and SREBP-1, respectively ${ }^{(57,58)}$. In addition, SREBP-2 preferentially activates cholesterol synthesis. $\operatorname{PPAR} \alpha$ plays an important role in the metabolic homeostasis of fatty acids through the regulation of target genes encoding enzymes for fatty acid $\beta$-oxidation and fatty acid transporters ${ }^{(59-62)}$. The rats fed a high-fructose diet and the EtOAc extract of amla did not show an altered expression of $\operatorname{PPAR} \alpha$, suggesting no significant role in fatty acid $\beta$-oxidation. On the other hand, the hepatic SREBP-1 protein level was increased, without changes in PPAR $\alpha$ and SREBP-2, resulting in the elevation of serum and hepatic TAG levels by the high-fructose diet. Miyazaki et al. ${ }^{(63)}$ also reported the induction of hepatic mRNA and protein levels of SREBP-1 and lipogenic gene expression including fatty acid synthase, acetyl-CoA carboxylase and stearoylCoA desaturase, whereas SREBP-2 proteins remained unchanged in mice following $7 \mathrm{~d}$ on a $60 \%$ fructose diet. However, the EtOAc extract of amla resulted in the suppression of the hepatic SREBP-1 protein level, which probably plays a crucial role in decreasing the hepatic TAG contents. These results suggest the possibility that the EtOAc extract of amla would lower the serum and hepatic TAG levels through a signalling pathway that regulates TAG synthesis but not the $\beta$-oxidation of fatty acids. On the other hand, although the hepatic total cholesterol content on high fructose feeding was significantly increased, the protein level of SREBP-2, a key transcription factor controlling cholesterol biosynthesis, was not affected by the high fructose feeding or administration of the EtOAc extract of amla. It is thought that the reduction of the hepatic total cholesterol content caused by the EtOAc extract of amla is not associated with hepatic cholesterol synthesis, but probably involved in other mechanisms such as cholesterol excretion.

Recent studies have shown that the metabolic syndrome is associated with the generation of reactive oxygen species (ROS) and reduction of certain antioxidants ${ }^{(64-70)}$. In addition, Delbosc et al. ${ }^{(71)}$ also reported that high fructose feeding is associated with an early (1 week) increase in ROS production by aorta, heart and circulatory polymorphonuclear cells, in association with enhanced markers of oxidative stress. Therefore, oxidative stress induced by a high-fructose diet is attributed to the metabolic syndrome, since a high-fructose diet alters lipid metabolism and dysregulation in the liver. The present results show that TBA-reactive substance levels in the serum and hepatic mitochondria were increased in rats fed a high-fructose diet. However, the EtOAc extract of amla reduced the elevated TBA-reactive substance levels in serum and hepatic mitochondria. Our previous study also provides supporting evidence that amla exhibits an antioxidative activity and protective effect against oxidative stress ${ }^{(34)}$ These results imply that the EtOAc extract of amla may ameliorate high fructose-induced metabolic syndrome by reducing oxidative stress, and this effect may be due to the antioxidant effect of the EtOAc extract of amla which contains polyphenols.

High levels of inflammation increase the risk of developing diabetes and atherosclerosis, and are thought to be a possible mechanism for the adverse consequences of the metabolic syndrome ${ }^{(72,73)}$. Therefore, we determined the effect of an EtOAc extract of amla on inflammatory protein levels caused by oxidative stress in the liver in a rat model with a high fructose-induced metabolic syndrome. Under resting conditions, NF- $\mathrm{BB}$ exists in the cytoplasm as a dimer bound to the inhibitory protein I- $\kappa \mathrm{B} \alpha$. Inducers of NF- $\mathrm{B}$, such as inflammatory cytokines, ROS and viral products, activate a dimeric $\mathrm{I}-\kappa \mathrm{B} \alpha$ kinase complex, causing the phosphorylation and ubiquitination of $I-\kappa B \alpha$ and its release from NF- $\kappa B$. The free $\mathrm{NF}-\kappa \mathrm{B}$ dimer translocates to the nucleus, where it regulates target gene transcription such as iNOS, COX-2, IL-6, IL-12 and TNF- $\alpha^{(74,75)}$. The activation of NF- $\kappa \mathrm{B}$ activity, in turn, up-regulates the synthesis of anti-apoptotic members, the bcl-2 family ${ }^{(76)}$, and increases the transcription of genes that encode protective enzymes such as iNOS and COX-2 ${ }^{(77)}$. Our data showed that the EtOAc extract of amla attenuated the increase of hepatic COX-2 protein by the fructose diet through regulation of the NF- $\mathrm{NB}$ signalling pathway. However, the EtOAc extract of amla did not alter the expressions of $\mathrm{I}-\kappa \mathrm{B} \alpha$ and $\mathrm{iNOS}$, indicating that there might be another mechanism regulating the $\mathrm{I}-\kappa \mathrm{B} \alpha$ and iNOS protein level. Moreover, in our present results, the bax protein level was significantly enhanced in the high fructose-induced metabolic syndrome rat model, while bcl-2 protein was significantly reduced compared with the normal rats. The oral 
administration of the EtOAc extract of amla has a beneficial effect on these proteins. These results suggest that the EtOAc extract of amla may reduce the severity of hepatic inflammation and liver cell injury induced by a high-fructose diet on regulating the related protein expression. It has been demonstrated that the disruption of the NF- $\mathrm{B}$ pathway under hypertriacylglycerolaemic and hyperglycaemic stress responses inhibits oxidative stress and inflammatory responses ${ }^{(3,54,69)}$. These findings indicate that the protective potential of the EtOAc extract of amla against the metabolic syndrome is attributed to the regulation of $\mathrm{COX}-2, \mathrm{NF}-\kappa \mathrm{B}$, bcl-2 and bax signalling pathways, and can be explained by its antioxidant effect derived from its polyphenolic constituents.

From the present study, we conclude that EtOAc extract of amla would improve high-fructose diet-induced metabolic syndrome, including hyperglycaemia, hyperlipidaemia and hypertension. The administration of the EtOAc extract of amla ameliorated the metabolic syndrome through the reduction of TAG and cholesterol concentrations, with the regulation of the hepatic SREBP-1 protein level and the suppression of inflammation by regulating the COX-2 and NF- $\mathrm{BB}$ protein levels. Further studies to identify active components in the polyphenol-rich fraction of amla should be conducted to elucidate the mechanism of its protective effect against the metabolic syndrome.

\section{Acknowledgements}

The present study was supported in part by Grants-in-Aid (C) from the Ministry of Education, Culture, Sports, Science, and Technology, Japan (no. 19500661 to T. Y.).

H. Y. K., T. O. and L. R. J. conducted the experimental work. T. Y. designed the experiment and wrote the manuscript.

The authors state that there are no conflicts of interest.

\section{References}

1. Levi B \& Werman MJ (1998) Long-term fructose consumption accelerates glycation and several age-related variables in male rats. J Nutr 128, 1442-1449.

2. Catena C, Giacchetti G, Novello M, et al. (2003) Cellular mechanisms of insulin resistance in rats with fructose-induced hypertension. Am J Hypertens 16, 973-978.

3. Kelley GL, Allan G \& Azhar S (2004) High dietary fructose induces a hepatic stress response resulting in cholesterol and lipid dysregulation. Endocrinology 145, 548-555.

4. Ackerman Z, Oron-Herman M, Grozovski M, et al. (2005) Fructose-induced fatty liver disease: hepatic effects of blood pressure and plasma triglyceride reduction. Hypertension $\mathbf{4 5}$, 1012-1018.

5. Basciano H, Federico L \& Adeli K (2005) Fructose, insulin resistance, and metabolic dyslipidemia. Nutr Metab 2, 5-18.

6. Hallfrisch J, Reiser S \& Prather ES (1983) Blood lipid distribution of hyperinsulinemic men consuming three levels of fructose. Am J Clin Nutr 37, 740-748.

7. Higley NA \& White JS (1991) Trends in fructose availability and consumption in the United States. Food Technol 45, $118-122$.

8. Gerrits PM \& Tsalikian E (1993) Diabetes and fructose metabolism. Am J Clin Nutr 58, 796S-799S.
9. Vuilleumier S (1993) Worldwide production of high-fructose syrup and crystalline fructose. Am J Clin Nutr 58, 733S-736S.

10. Uusitupa MI (1994) Fructose in the diabetic diet. Am J Clin Nutr 59, 753S-757S.

11. Smith SM (1998) High fructose corn syrup replaces sugar in processed food. Environ Nutr 11, 7-8.

12. Elliott SS, Keim NL, Stern JS, et al. (2002) Fructose, weight gain, and the insulin resistance syndrome. Am J Clin Nutr 76, 911-922.

13. Hwang IS, Ho H, Hoffman BB, et al. (1987) Fructose-induced insulin resistance and hypertension in rats. Hypertension 10, $512-516$.

14. Reaven GM (1988) Banting lecture 1988. Role of insulin resistance in human disease. Diabetes 37, 1595-1607.

15. Dimo T, Rakotonirina A, Tan PV, et al. (2001) Antihypertensive effects of Dorstenia psilurus extract in fructose-fed hyperinsulinemic, hypertensive rats. Phytomedicine $\mathbf{8}$, $101-106$.

16. Al-Awwadi NA, Bornet A, Azay J, et al. (2004) Red wine polyphenols alone or in association with ethanol prevent hypertension, cardiac hypertrophy, and production of reactive oxygen species in the insulin-resistant fructose-fed rat. J Agric Food Chem 52, 5593-5597.

17. Kang DG, Moon MK, Sohn EJ, et al. (2004) Effects of morin on blood pressure and metabolic changes in fructose-induced hypertensive rats. Biol Pharm Bull 27, 1779-1783.

18. Wu LY, Juan CC, Hwang LS, et al. (2004) Green tea supplementation ameliorates insulin resistance and increases glucose transporter IV content in a fructose-fed rat model. Eur $J$ Nutr 43, 116-124.

19. Al-Awwadi NA, Araiz C, Bornet A, et al. (2005) Extracts enriched in different polyphenolic families normalize increased cardiac NADPH oxidase expression while having differential effects on insulin resistance, hypertension, and cardiac hypertrophy in high-fructose-fed rats. J Agric Food Chem 53, 151-157.

20. Miatello R, Vazquez M, Renna N, et al. (2005) Chronic administration of resveratrol prevents biochemical cardiovascular changes in fructose-fed rats. Am J Hypertens 18, 864-870.

21. Li RW, Douglas TD, Maiyoh GK, et al. (2006) Green tea leaf extract improves lipid and glucose homeostasis in a fructosefed insulin-resistant hamster model. J Ethnopharmacol 104, $24-31$.

22. Thakur CP (1985) Emblica officinalis reduces serum, aortic and hepatic cholesterol in rabbits. Experientia 41, 423-424.

23. Deokar AB (1998) 125 Medicinal Plants Grown at Rajagaon, 1st ed., pp. 48-49. Pune: DS Manav Vikas Foundation.

24. Perry LM (1980) Medicinal Plants of East and South East Asia: Attributed Properties and Uses, pp. 149-150. Cambridge, MA: MIT Press.

25. Anila L \& Vijayalakshmi NR (2002) Flavonoids from Emblica officinalis and Mangifera indica - effectiveness for dyslipidemia. J Ethnopharmacol 79, 81-87.

26. Sabu MC \& Kuttan R (2002) Anti-diabetic activity of medicinal plants and its relationship with their antioxidant property. J Ethnopharmacol 81, 155-160.

27. Asmawi MZ, Kankaanranta H, Moilanen E, et al. (1993) Antiinflammatory activities of Emblica officinalis Gaertn leaf extracts. J Pharm Pharmacol 45, 581-584.

28. El-Mekkawy S, Meselhy MR, Kusumoto IT, et al. (1995) Inhibitory effects of Egyptian folk medicines on human immunodeficiency virus (HIV) reverse transcriptase. Chem Pharm Bull 43, 641-648.

29. Jose JK, Kuttan G \& Kuttan R (2001) Antitumour activity of Emblica officinalis. J Ethnopharmacol 75, 65-69.

30. Bandyopadhyay SK, Pakrashi SC \& Pakrashi A (2000) The role of antioxidant activity of Phyllanthus emblica fruits on prevention 
from indomethacin induced gastric ulcer. $J$ Ethnopharmacol 70, $171-176$.

31. Bhattacharya A, Chatterjee A, Ghosal S, et al. (1999) Antioxidant activity of active tannoid principles of Emblica officinalis (amla). Indian J Exp Biol 37, 676-680.

32. Anila L \& Vijayalakshmi NR (2003) Antioxidant action of flavonoids from Mangifera indica and Emblica officinalis in hypercholesterolemic rats. Food Chem 83, 569-574.

33. Jose JK \& Kuttan R (1995) Antioxidant activity of E. officinalis. $J$ Clin Biochem Nutr 19, 63-70.

34. Kim HJ, Yokozawa T, Kim HY, et al. (2005) Influence of amla (Emblica officinalis Gaertn.) on hypercholesterolemia and lipid peroxidation in cholesterol-fed rats. J Nutr Sci Vitaminol 51, 413-418.

35. Yokozawa T, Kim HY, Kim HJ, et al. (2007) Amla (Emblica officinalis Gaertn.) prevents dyslipidemia and oxidative stress in the ageing process. Br J Nutr 97, 1187-1195.

36. Yokozawa T, Kim HY, Kim HJ, et al. (2007) Amla (Emblica officinalis Gaertn.) attenuates age-related renal dysfunction by oxidative stress. J Agric Food Chem 55, 7744-7752.

37. National Research Council (1996) Guide for the Care and Use of Laboratory Animals. Bethesda, MD: National Institutes of Health.

38. Havel RJ, Eder HA \& Bragdon JH (1955) The distribution and chemical composition of ultracentrifugally separated lipoproteins in human serum. J Clin Invest 34, 1345-1353.

39. McFarland KF, Catalano EW, Day JF, et al. (1979) Nonenzymatic glucosylation of serum proteins in diabetes mellitus. Diabetes 28, 1011-1014.

40. Naito C \& Yamanaka T (1978) Lipid peroxides in atherosclerotic diseases. Nippon Ronen Igakkai Zasshi 15, 187-191.

41. Folch J, Lees M \& Sloane Stanley GH (1957) A simple method for the isolation and purification of total lipides from animal tissues. J Biol Chem 226, 497-509.

42. Johnson D \& Lardy H (1967) Isolation of liver or kidney mitochondria. Methods Enzymol X, 94-96.

43. Jung K \& Pergande M (1985) Influence of cyclosporin A on the respiration of isolated rat kidney mitochondria. FEBS Lett 183, $167-169$.

44. Buege JA \& Aust SD (1978) Microsomal lipid peroxidation. Methods Enzymol 52, 302-310.

45. Itzhaki RF \& Gill DM (1964) A micro-biuret method for estimating proteins. Anal Biochem 9, 401-410.

46. Sakurai H, Hisada Y, Ueno M, et al. (1996) Activation of transcription factor NF- $\mathrm{KB}$ in experimental glomerulonephritis in rats. Biochim Biophys Acta 1316, 132-138.

47. Laemmli UK (1970) Cleavage of structural proteins during the assembly of the head of bacteriophage T4. Nature 227, $680-685$.

48. Zhang YJ, Tanaka T, Yang CR, et al. (2001) New phenolic constituents from the fruit juice of Phyllanthus emblica. Chem Pharm Bull 49, 537-540.

49. Tobey TA, Mondon CE, Zavaroni I, et al. (1982) Mechanism of insulin resistance in fructose-fed rats. Metabolism 31, 608-612.

50. Thorburn AW, Storlien LH, Jenkins AB, et al. (1989) Fructoseinduced in vivo insulin resistance and elevated plasma triglyceride levels in rats. Am J Clin Nutr 49, 1155-1163.

51. Hallfrisch J (1990) Metabolic effects of dietary fructose. FASEB $J$ 4, 2652-2660.

52. Fried SK \& Rao SP (2003) Sugars, hypertriglyceridemia, and cardiovascular disease. Am J Clin Nutr 78, 873S-880S.

53. Sarti C \& Gallagher J (2006) The metabolic syndrome: prevalence, CHD risk, and treatment. J Diabetes Complications 20 , $121-132$.
54. Dichtl W, Nilsson L, Goncalves I, et al. (1999) Very lowdensity lipoprotein activates nuclear factor $-\kappa \mathrm{B}$ in endothelial cells. Circ Res 84, 1085-1094.

55. Ginsberg HN (2002) New perspectives on atherogenesis: role of abnormal triglyceride-rich lipoprotein metabolism. Circulation 106, 2137-2142.

56. Williams CM, Maitin V \& Jackson KG (2004) Triacylglycerolrich lipoprotein-gene interactions in endothelial cells. Biochem Soc Trans 32, 994-998.

57. Kersten S, Desvergne B \& Wahli W (2000) Roles of PPARs in health and disease. Nature 405, 421-424.

58. Roglans N, Sanguino E, Peris C, et al. (2002) Atorvastatin treatment induced peroxisome proliferator-activated receptor $\alpha$ expression and decreased plasma nonesterified fatty acids and liver triglyceride in fructose-fed rats. J Pharmacol Exp Ther 302, 232-239.

59. Schoonjans K, Martin G, Staels B, et al. (1997) Peroxisome proliferator-activated receptors, orphans with ligands and functions. Curr Opin Lipidol 8, 159-166.

60. Aoyama T, Peters JM, Iritani N, et al. (1998) Altered constitutive expression of fatty acid-metabolizing enzymes in mice lacking the peroxisome proliferator-activated receptor $\alpha$ (PPAR $\alpha$ ). J Biol Chem 273, 5678-5684.

61. Palmer CN, Hsu MH, Griffin KJ, et al. (1998) Peroxisome proliferator activated receptor- $\alpha$ expression in human liver. Mol Pharmacol 53, 14-22.

62. Leone TC, Weinheimer CJ \& Kelly DP (1999) A critical role for the peroxisome proliferator-activated receptor $\alpha(\operatorname{PPAR} \alpha)$ in the cellular fasting response: the PPAR $\alpha$-null mouse as a model of fatty acid oxidation disorders. Proc Natl Acad Sci U S A 96, 7473-7478.

63. Miyazaki M, Dobrzyn A, Man WC, et al. (2004) Stearoyl-CoA desaturase 1 gene expression is necessary for fructose-mediated induction of lipogenic gene expression by sterol regulatory element-binding protein-1c-dependent and -independent mechanisms. J Biol Chem 279, 25164-25171.

64. Aljada A, Garg R, Ghanim H, et al. (2001) Nuclear factor- $к B$ suppressive and inhibitor- $\mathrm{kB}$ stimulatory effects of troglitazone in obese patients with type 2 diabetes: evidence of an anti-inflammatory action? J Clin Endocrinol Metab 86, 3250-3256.

65. Ghanim H, Garg R, Aljada A, et al. (2001) Suppression of nuclear factor- $\kappa \mathrm{B}$ and stimulation of inhibitor $\kappa \mathrm{B}$ by troglitazone: evidence for an anti-inflammatory effect and a potential antiatherosclerotic effect in the obese. J Clin Endocrinol Metab 86, 1306-1312.

66. Browning JD \& Horton JD (2004) Molecular mediators of hepatic steatosis and liver injury. J Clin Invest 114, 147-152.

67. Furukawa S, Fujita T, Shimabukuro M, et al. (2004) Increased oxidative stress in obesity and its impact on metabolic syndrome. J Clin Invest 114, 1752-1761.

68. Sonnenberg GE, Krakower GR \& Kissebah AHA (2004) A novel pathway to the manifestations of metabolic syndrome. Obes Res 12, 180-186.

69. Stentz FB, Umpierrez GE, Cuervo R, et al. (2004) Proinflammatory cytokines, markers of cardiovascular risks, oxidative stress, and lipid peroxidation in patients with hyperglycemic crises. Diabetes 53, 2079-2086.

70. Dandona P, Aljada A, Chaudhuri A, et al. (2005) Metabolic syndrome: a comprehensive perspective based on interactions between obesity, diabetes, and inflammation. Circulation 111, 1448-1454.

71. Delbosc S, Paizanis E, Magous R, et al. (2005) Involvement of oxidative stress and NADPH oxidase activation in the development of cardiovascular complications in a model of insulin resistance, the fructose-fed rat. Atherosclerosis 179, 43-49. 
72. Barzilay JI, Abraham L, Heckbert SR, et al. (2001) The relation of markers of inflammation to the development of glucose disorders in the elderly: the Cardiovascular Health Study. Diabetes 50, 2384-2389.

73. Pradhan AD, Manson JE, Rifai N, et al. (2001) C-reactive protein, interleukin 6 , and risk of developing type 2 diabetes mellitus. JAMA 286, 327-334.

74. Baldwin AS (2001) The transcription factor NF-кB and human disease. J Clin Invest 107, 3-6.
75. Li Q \& Verma IM (2002) NF- $\mathrm{B}$ regulation in the immune system. Nat Rev Immunol 2, 725-734.

76. Sasaki M, Kumazaki T, Takano H, et al. (2001) Senescent cells are resistant to death despite low Bcl-2 level. Mech Ageing Dev 122, 1695-1706.

77. Chung HY, Kim HJ, Kim KW, et al. (2002) Molecular inflammation hypothesis of aging based on the anti-aging mechanism of calorie restriction. Microsc Res Tech 59, 264-272. 